\title{
Levenberg-Marquardt 法による可解性を問わない逆運動学
}

\author{
杉 原 知 道*
}

\author{
Solvability-unconcerned Inverse Kinematics by Levenberg-Marquardt Method
}

Tomomichi Sugihara*

\begin{abstract}
A robust numerical solution to the inverse kinematics is proposed based on Levenberg-Marquardt method, where the squared norm of the residual with a small bias is used for the damping factor. A rather simple idea remarkably improves numerical stability and convergence performance even in unsolvable cases. The discussion is done through an investigation of the condition number of coefficient matrix. Comparison tests with the conventional methods show that only the proposed method succeeds in all cases. It frees operators from being careful about the target position-orientation assignment of effectors, so that it facilitates easy robot motion designs and remote operations.
\end{abstract}

Key Words: Inverse Kinematics, Levenberg-Marquardt Method, Adaptive Damping, Numerical Robustness

\section{1. は じめに}

逆運動学は, ロボット工学における基本計算でありながら, 未 だ困難をはらむ問題である。ロボット身体上のある関心リンク (エフェクタ等) の位置・姿勢等に関する拘束条件を満たす関節 変位を求める, というのが題意であるが, Pieper [1] が指摘した ように, これは連立多元多次方程式の求解問題に帰着する. 特 別な機構 [1]〜 [4] を除いて解を解析的に得ることは難しく, 多 くは数值解法に頼ることになる。

数值解法としては, 反復計算である Newton-Raphson 法 （NR 法）がよく用いられる.これに必要な基礎ヤコビ行列 [5] の効率的な計算方法はすでに示されている [6] [7]. しかし NR 法による計算が成功するのは, 元の方程式を表す関数に逆関数 が存在し, かつ元の方程式が可解である場合に限られる。逆運 動学の観点から言えば，前者はロボットが非圥長，すなわち拘 束条件の数がロボットの自由度に一致し, かつ初期姿勢から解 となる姿勢に至る間に特異点を通らないことを意味する。後者 は, 拘束条件として与えられた関心リンクの位置・姿勢が作業 空間内になければならないということである。これらの制約に より，NR 法は初期值依存性が高く大域的収束性を持たない方 法となっている。

特異点の問題はヤコビ行列の性質と密接に関係し, 従来より 主に微分逆運動学の研究において議論されてきた [6] [8]〜 [12]. Whitney [6] は Moore-Penrose の一般逆行列（MP 逆行列）を

原稿受付 2009 年 12 月 19 日

*大阪大学大学院工学研究科

* Graduate School of Engineering, Osaka University

ロ 本論文は有用性で評価されました。
用い，これを解決することを提案した，MP 逆行列解はヤコビ行 列の階数にかかわらず求まり, 方程式の残差を最小化するよう な最小の関節相対変位を与える働きを持つ. 中村・花房 [10] は, この方法では特異点近傍で関節変位にチャタリングを生じる問題 が解決されないことを指摘し, 減衰因子を導入した特異点低感度 逆行列（SR 逆行列）を提案した. Wampler [11] も同様の方法 を提案し，それが Levenberg-Marquardt 法（LM 法） [13] [14] の枠組みに含まれることに言及している.

可解性の問題は, 特異点の問題と同様に深刻である. 特に困 難なことに, 大抵の場合, 方程式が可解であるか否かを事前に知 る手段はほとんどない。例えば人型ロボットのような大規模な 構造可変リンク系 $[15]$ の運動設計や遠隔操縦において, 不可解 とならないよう慎重に関心リンクの目標位置·姿勢を配置するこ とは, 運動設計者や操縦者にとって重荷となる。この観点から, 逆運動学を方程式の残差最小化問題に置き換えることは合理的 である. 最小化問題の解法として最急降下法（SD 法）[16] [17] や可変計量法（VM 法） [18] [19] を用いる方法が提案されてい るが，前者は収束が遅く，また後者はしばしば極小に陷るため 信頼性に欠けるという問題がある。微分逆運動学を反復計算の 1 ステップとして利用する勾配法が比較的高速に解を得る方法 となり, なかでも LM 法は計算の安定性の点で優れている.こ のとき, 収束性能は減衰因子の選び方に依存するが, このよう な観点からの議論はこれまでにあまりなされていない.

本稿では, LM 法による逆運動学解法を特異点問題, 可解性問 題のいずれに対してもロバストなものとし，かつ高い収束性能 を実現する減衰因子の選び方を提案する。残差の自乗ノルムを 減衰因子に用いる単純な方法によって, 計算のロバスト性と収 束性能の双方を良好にすることが可能である。これに似た方法 
は Chan and Lawrence [20] によっても提案されているが, 関 心リンクの目標位置・姿勢が特異点近傍に設定されたときに計 算が不安定になる問題があった。本稿で提案する方法では, 減 衰因子に微小なバイアスを加えることによってこの問題を解決 している. 12 自由度の圥長マニピュレータモデルを用いて従来 法との比較を行い, 特に提案方法のみがすべての試験において 求解に成功したことを示す.

\section{2.レビュー：最小化による逆運動学へのアプローチ}

本章では, 逆運動学の数值解法に関する先行研究, 特に最小 化問題への変形によるアプローチを整理する.

運動学は, 関節変位ベクトル $\boldsymbol{q}=\left[\begin{array}{llll}q_{1} & q_{2} & \cdots & q_{n}\end{array}\right]^{\mathrm{T}} \in \mathbb{R}^{n}$ に 課せられる代数的拘束条件の組で表現される。ただし $n$ は関節 数であり，関節可動範囲の制約については今は考えない，まず, $i$ 番目拘束条件の残差 $\boldsymbol{e}_{i} \in \mathbb{R}^{3}$ を次のように定義する.

$$
\boldsymbol{e}_{i}(\boldsymbol{q}) \equiv \begin{cases}{ }^{d} \boldsymbol{p}_{i}-\boldsymbol{p}_{i}(\boldsymbol{q}) & \text { (位置拘束) } \\ \boldsymbol{a}\left({ }^{d} \boldsymbol{R}_{i} \boldsymbol{R}_{i}(\boldsymbol{q})^{\mathrm{T}}\right) & \text { (姿勢拘束) }\end{cases}
$$

ただし $\boldsymbol{p}_{i} \in \mathbb{R}^{3},{ }^{d} \boldsymbol{p}_{i} \in \mathbb{R}^{3}$ は関心点の位置とその目標位置, $\boldsymbol{R}_{i} \in S O(3),{ }^{d} \boldsymbol{R}_{i} \in S O(3)$ は関心リンクの姿勢とその目標姿 勢であり，任意の $\boldsymbol{R} \in S O(3)$ に対し $\boldsymbol{a}(\boldsymbol{R}) \in \mathbb{R}^{3}$ は等価角軸 ベクトルを意味する，等価角軸ベクトルの計算方法については 付録 A に記す．拘束条件には作業内容に由来するものと閉ルー プ等の機構に由来するものがあるが，ここでそれらを区別する 必要はない. 全拘束条件の数を $3 m$ とし, 全体の残差べクトル $\boldsymbol{e}(\boldsymbol{q}) \in \mathbb{R}^{3 m}$ を次のように定義しよう.

$$
\boldsymbol{e}(\boldsymbol{q}) \equiv\left[\begin{array}{llll}
\boldsymbol{e}_{1}^{\mathrm{T}}(\boldsymbol{q}) & \boldsymbol{e}_{2}^{\mathrm{T}}(\boldsymbol{q}) & \cdots & \boldsymbol{e}_{m}^{\mathrm{T}}(\boldsymbol{q})
\end{array}\right]^{\mathrm{T}}
$$

逆運動学は次の非線形方程式を解くことに帰着する.

$$
e(\boldsymbol{q})=\mathbf{0}
$$

従来の NR 法に基づく逆運動学では, 適当な初期值 $\boldsymbol{q}_{0}$ から出 発し, 次の更新則によって式（3）を満たす $\boldsymbol{q}=\boldsymbol{q}^{*}$ へ至ること を試みる。

$$
\boldsymbol{q}_{k+1}=\boldsymbol{q}_{k}-\nabla \boldsymbol{e}\left(\boldsymbol{q}_{k}\right)^{-1} \boldsymbol{e}_{k}
$$

ただし $k$ は反復回数であり, $\boldsymbol{e}_{k} \equiv \boldsymbol{e}\left(\boldsymbol{q}_{k}\right)$ とした. $\nabla \boldsymbol{e}$ を, 基 礎ヤコビ行列 $\boldsymbol{J}(\boldsymbol{q})$ を用いて次のように置き換えても構わない.

$$
\nabla \boldsymbol{e}\left(\boldsymbol{q}_{k}\right) \simeq-\boldsymbol{J}_{k}
$$

ただし $\boldsymbol{J}_{k} \equiv \boldsymbol{J}\left(\boldsymbol{q}_{k}\right)$ とした。 ここにおいて，次の三つの条件が 暗に仮定されている。すなわち，

i）拘束条件の数とロボットの自由度は一致している i.e. $n=$ $3 m$

ii） $\boldsymbol{J}_{k}$ は常に正則である

iii）方程式（3）は解を持つ

これらのうちいずれか一つでも破られれば, 反復計算は破綻する.

\footnotetext{
†これは 3 階のテンソルであり,ヘッセ行列やその行列式と混同しないよ
} う注意が必要である。
不可解な場合でも破綻しない逆運動学を議論するために, 元 の方程式（3）を次の最小化問題（QP） で置き換えよう.

$$
E(\boldsymbol{q}) \equiv \frac{1}{2} \boldsymbol{e}^{\mathrm{T}} \boldsymbol{W}_{E} \boldsymbol{e} \rightarrow \min
$$

ただし $\boldsymbol{W}_{E}=\operatorname{diag}\left\{w_{E, i}\right\}\left(w_{E, i}>0\right.$ for $\left.\forall i=1 \sim 3 m\right)$ は拘 束条件に対する重み行列であり, 個々の拘束条件の物理次元や優 先度の違いを吸収するものである。これの設定について本稿では 深く議論はしないが, 次元の違いに対処する方法として, 例えば 長さの次元をとる拘束条件については代表長さの逆数, 角度の次 元をとる拘束条件については $1.0 / 2 \pi$ とするなどが考えられる.

もちろん, このような問題の置換は本来等価なものではなく, 真の解を見つけることよりも，計算が異常終了することを防ぎ 実用上の安全性を優先することを含意する。ここで次の重要な 事実を指摘しておこう。最小化問題に勾配法を適用すると, 計 算が収束するならばその収束点においては $\nabla E=\mathbf{0}^{\mathrm{T}}$ が成り立 つ. $E(\boldsymbol{q})$ の定義より，

$$
\nabla E=\boldsymbol{e}^{\mathrm{T}} \boldsymbol{W}_{E} \nabla \boldsymbol{e} \simeq-\boldsymbol{e}^{\mathrm{T}} \boldsymbol{W}_{E} \boldsymbol{J}
$$

であるから，明らかに収束值は真の解でなければ特異点となる． したがって元の方程式が不可解な場合, 特異点問題は避けるこ とができない.

問題 (QP) に対しても, NR 法は式 (4) とは若干異なる形 で利用できる。式（6）をさらに微分すると次を得る。

$$
\begin{aligned}
\nabla^{2} E & =\nabla \boldsymbol{e}^{\mathrm{T}} \boldsymbol{W}_{E} \nabla \boldsymbol{e}+\sum_{i=1}^{n} \frac{\partial \nabla \boldsymbol{e}}{\partial q_{i}} \boldsymbol{W}_{E} \boldsymbol{e} \\
& \simeq \boldsymbol{J}^{\mathrm{T}} \boldsymbol{W}_{E} \boldsymbol{J}-\sum_{i=1}^{n} \frac{\partial \boldsymbol{J}}{\partial q_{i}} \boldsymbol{W}_{E} \boldsymbol{e}
\end{aligned}
$$

$\partial \boldsymbol{J} / \partial q_{i}$ はマニピュレータ・ヘシアン [21]〜 [23] と呼ばれる. $\mathrm{NR}$ 法による更新則は, これらを用いて次のように与えられる。

$$
\begin{gathered}
\boldsymbol{q}_{k+1}=\boldsymbol{q}_{k}+\left(\boldsymbol{J}_{k}^{\mathrm{T}} \boldsymbol{W}_{E} \boldsymbol{J}_{k}-\sum_{i=1}^{n} \frac{\partial \boldsymbol{J}_{k}}{\partial q_{i}} \boldsymbol{W}_{E} \boldsymbol{e}_{k}\right)^{-1} \boldsymbol{g}_{k} \\
\boldsymbol{g}_{k} \equiv \boldsymbol{J}_{k}^{\mathrm{T}} \boldsymbol{W}_{E} \boldsymbol{e}_{k}
\end{gathered}
$$

ただし式（5）を用いた。この方法は Deo and Walker [24]に よって提案された。しかしこれは計算量を必要とする上に, 係 数行列が正定值とは限らないため $E$ の減少性を保証せず, 大域 的収束性を持たないという欠点が依然として存在している.今, 我々の目的は $E$ の詳細な曲率を調べることではなく $E$ の降下 方向を得ることであるから, 式 $(8)$ のように $\nabla^{2} E$ を直接使う のではなく，適当な正定值行列で代用するほうが望ましい.

式（7）のあとの項を省略すると, これは Gauss-Newton 法 (GN 法) と呼ばれる方法 $[25]$ と等価であり，更新則は次のよ うになる。

$$
\boldsymbol{q}_{k+1}=\boldsymbol{q}_{k}+\left(\boldsymbol{J}_{k}^{\mathrm{T}} \boldsymbol{W}_{E} \boldsymbol{J}_{k}\right)^{-1} \boldsymbol{g}_{k}
$$

これは式 (4) において, $\nabla \boldsymbol{e}\left(\boldsymbol{q}_{k}\right)^{-1}$ の代わりに $\boldsymbol{J}_{k}$ の重み付き) ルム最小一般逆行列を用いることとも等価であり, 圥長マニピュ 
レータの微分逆運動学の解として Anderson and Angeles [26] により提案された，更新則（10）は， $\boldsymbol{J}_{k}$ がフルランクでないと き,すなわち特異点においては適用できないが, MP 逆行列を 用いる方法 [6] で置き換えればこれは問題にならない.しかし中 村・花房 [10] が指摘したとおり, 問題はむしろ特異点の近傍に おいて数值的に不安定化することにある. 文献 [24] では式 (8) を特異点の近傍でのみ用い, それ以外は式（10）を用いること も提案されているが，ロボットの姿勢が特異点の近傍にあるか 否かを毎回判別する必要が生じ, 計算コストの面で不利である.

LM 法 [13] [14] はこのような問題を解決する方法であり, 次 の更新則によって定義される.

$$
\begin{gathered}
\boldsymbol{q}_{k+1}=\boldsymbol{q}_{k}+\boldsymbol{H}_{k}^{-1} \boldsymbol{g}_{k} \\
\boldsymbol{H}_{k} \equiv \boldsymbol{J}_{k}^{\mathrm{T}} \boldsymbol{W}_{E} \boldsymbol{J}_{k}+\boldsymbol{W}_{N}
\end{gathered}
$$

$\boldsymbol{W}_{N}=\operatorname{diag}\left\{w_{N, i}\right\}\left(w_{N, i}>0\right.$ for $\left.\forall i=1 \sim n\right)$ を減衰因子 と呼ぶ. LM 法を用いた逆運動学は Goldenberg ら [27]に提案 されたＮNR 法に対し LM 法は，マニピュレータ・ヘシアンの 計算を必要とせず, しかも $\boldsymbol{H}_{k}$ は常に正則かつ正定值行列とな り, 式 (12) に扔ける増分項は必ず降下方向を向くので, $E$ の 減少性が保証される。 これは Tikhonov 正則化 [28] の最も単純 な形であり, 次の混合最小化問題を毎回の反復計算で解いてい るとも解釈できる $[10]$.

$$
\frac{1}{2} \boldsymbol{r}_{k}^{\mathrm{T}} \boldsymbol{W}_{E} \boldsymbol{r}_{k}+\frac{1}{2} \Delta \boldsymbol{q}_{k}^{\mathrm{T}} \boldsymbol{W}_{N} \Delta \boldsymbol{q}_{k} \rightarrow \min .
$$

ただし $\Delta \boldsymbol{q}_{k} \equiv \boldsymbol{q}_{k+1}-\boldsymbol{q}_{k}, \boldsymbol{r}_{k} \equiv \boldsymbol{e}_{k}-\boldsymbol{J}_{k} \Delta \boldsymbol{q}_{k}$ である。このた め乤長系であっても, ある解に最小の関節相対変位で収束する。

\section{3. 改良誤差減衰最小二乗法による逆運動学}

LM 法に扔いては，減衰因子 $\boldsymbol{W}_{N}$ の性質が計算結果に大きく 影響を及ぼす， $\boldsymbol{W}_{N}$ の選び方については，定数とするもの [11], 可操作度 [29] を用いるもの [10] [30], 係数行列の最小特異值を 一定值以上に抑えるもの [31] [32], 係数行列の条件数を一定值 以下に抑えるもの [33] [34], 関節変位の増分を陽に制限するも の [35] [36], 優先度の高い拘束条件の残差の随伴ベクトルを用 いるもの [37] 等, 多くの提案がなされている. これらは微分逆 運動学の観点から局所的な数值条件を良好に保つために考えら れたもので, 反復計算の収束性能の観点からはほとんど議論さ れていない. 一方, Chan and Lawrence [20]は減衰係数を次 式で定義する誤差減衰最小二乗法を提案した。

$$
\boldsymbol{W}_{N}=\lambda E_{k} \mathbf{1}
$$

ただし $\lambda$ は定数係数であり, $\lambda=1$ としても構わない. また $E_{k} \equiv E\left(q_{k}\right)$ であり, $\mathbf{1}$ は $n \times n$ 単位行列である. 元の方程式 が可解ならば, $\boldsymbol{q}_{k}$ が解に収束する過程で $E_{k}$ は零に二次収束す るので, 反復計算は超一次収束することが期待される [38]. し かし解が特異点に近い場合, 収束するにつれて係数行列は悪条 件化してしまうという問題がある. 提案方法は，これを次のよ うに修正するものである。

$$
\boldsymbol{W}_{N}=E_{k} \mathbf{1}+\overline{\boldsymbol{W}}_{N}
$$

ただし $\overline{\boldsymbol{W}}_{N}=\operatorname{diag}\left\{\bar{w}_{N, i}\right\}, \quad\left(\bar{w}_{N, i}>0\right.$ for $\left.\forall i=1 \sim n\right)$ は微 小なバイアス量である.

簡単のため, すべての $\bar{w}_{N, i}$ が等しく $\bar{w}_{N}$ である，すなわち $\overline{\boldsymbol{W}}_{N}=\bar{w}_{N} \mathbf{1}$ とし, $\boldsymbol{W}_{E}^{1 / 2} \boldsymbol{J}_{k}$ を次のように特異值分解したと しょう.

$$
\boldsymbol{W}_{E}^{1 / 2} \boldsymbol{J}_{k}=\boldsymbol{U} \boldsymbol{\Sigma} \boldsymbol{V}^{\mathrm{T}}
$$

ただし $\boldsymbol{W}_{E}^{1 / 2}=\operatorname{diag}\left\{\sqrt{w_{N, i}}\right\}$ を意味し， $\boldsymbol{U}, \boldsymbol{V}$ は正規直交 行列, $\boldsymbol{\Sigma}=\operatorname{diag}\left\{\sigma_{i}\right\}$ は特異值を対角成分に降順に並べた正方 行列（すなわち $\sigma_{1} \geq \sigma_{2} \geq \cdots \geq \sigma_{n}$ ）である.このとき，

$$
\begin{aligned}
\boldsymbol{H}_{k} & =\boldsymbol{V} \boldsymbol{\Sigma} \boldsymbol{U}^{\mathrm{T}} \boldsymbol{U} \boldsymbol{\Sigma} \boldsymbol{V}^{\mathrm{T}}+\left(E_{k}+\bar{w}_{N}\right) \mathbf{1} \\
& =\boldsymbol{V}\left\{\boldsymbol{\Sigma}^{2}+\left(E_{k}+\bar{w}_{N}\right) \mathbf{1}\right\} \boldsymbol{V}^{\mathrm{T}}
\end{aligned}
$$

なので, $\boldsymbol{H}_{k}$ の条件数 $\kappa$ は次のようになる.

$$
\kappa=\frac{\sigma_{1}^{2}+E_{k}+\bar{w}_{N}}{\sigma_{n}^{2}+E_{k}+\bar{w}_{N}}
$$

これより次のことが言える。

I）方程式（3）が可解であり, 解が特異点から離れていれば, $\boldsymbol{W}_{N}$ は $\overline{\boldsymbol{W}}_{N}$ に二次収束する。 $\overline{\boldsymbol{W}}_{N}$ が十分小さいならば, Chan らの方法と同様に反復計算は超一次収束する.

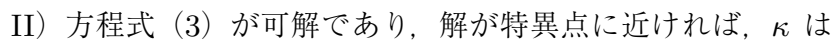
$\left(\sigma_{1}^{2}+\bar{w}_{N}\right) / \bar{w}_{N}$ に近づく. したがって $\bar{w}_{N}$ は $\boldsymbol{H}_{k}$ の退化 を防ぐために必要である。

III）方程式 (3) が不可解ならば, $\boldsymbol{e}_{k}$ の増加に伴って $\kappa$ は 1 に近づく，すなわち収束時の残差 $\boldsymbol{e}_{k}$ が大きいほど計算は 安定に行えるという興味梁い事実が示唆される。これは $\left\|\boldsymbol{H}_{k}^{-1} \boldsymbol{g}_{k}\right\| \simeq 1 /\left\|\boldsymbol{e}_{k}\right\|$ となることからも推察される.

$\bar{w}_{N}$ の定め方には議論の余地があるが，その効果が現れるのは， 解が特異点近辺にある場合（上記 II）のみであり，その他の場 合では，上記 I に述べたように小さいほど収束性が向上する。 したがって最悪の場合での条件数 $\left(\sigma_{1}^{2}+\bar{w}_{N}\right) / \bar{w}_{N}$ に基づいて, どの程度小さい值まで許容できるか考慮すべきだが, $\sigma_{1}^{2}$ は拘 束条件の数や物理次元にも依存するため, それほど簡単に見積 もれるものではない，しかし筆者が試験した計算環境では, 位 置・姿勢が混在した拘束条件の数が $3 \sim 30$ 程度の状況におい ては, 経験的に, ロボットの代表リンク長 $l$ に対して $\bar{w}_{N} \simeq$ $1.0 \times 10^{-1} \sim 1.0 \times 10^{-3} l^{2}$ 程度ならば十分ロバストに計算が 収束するという知見を $l=0.1 \sim 100[\mathrm{~m}]$ の範囲で得ている.

一般的に LM 法に扔いて大域的収束性を保証するためには, Moré-Thuente 法 [39] などの直線探索アルゴリズムと組み合わ せる必要があると言われる。 しかしながら次章において, 提案 方法が直線探索を併用しなくても十分な収束性能を持つことが 実験的に示される。

\section{4. 評 価}

Fig. 1 に示すような冗長マニピュレータモデルを用いて, 収束 性能㧍よび計算時間の観点から提案方法を評価した。 このモデル は五つのリンクが四つの球面関節によって直鎖状に連結され, 12 自由度を持つ. 各関節間の長さはすべて $0.15[\mathrm{~m}]$, エフェクタ関 節中心からエンドポイントまでの長さは $0.05[\mathrm{~m}]$ である. 以下 において, エフェクタ位置とはエンドポイント位置を意味する。 

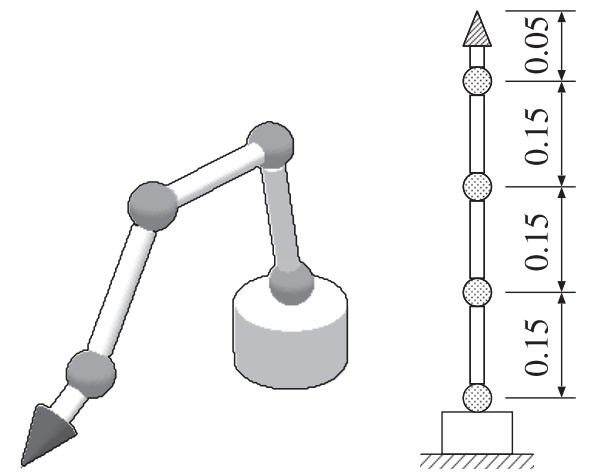

Fig. 1 Kinematics model of the tested manipulator comprising five links and four spherical joints. The lengths of the three links from the root are all $0.15[\mathrm{~m}]$, while the endeffector's length is $0.05[\mathrm{~m}]$

比較のために, 次に挙げる 12 種の方法について試験を行った.

- SD: 最急降下法 *

・GN: 重み付き MP 逆行列を用いた GN 法 ${ }^{* *}$

- LM $(\lambda=0.001,0.01,0.1): \boldsymbol{W}_{N}=\lambda \mathbf{1}$ において $\lambda$ を定 数とした LM 法 (3 種)

- LM (NH) : 中村・花房の方法 [10]による LM 法 ${ }^{* * *}$

- LM (MWM) : Mayorga-Wong-Milano の方法 [34]によ る LM 法 ${ }^{* * *}$

- LM (Chi）：Chiaverini の方法 [31] による LM 法 ${ }^{* * *}$

- LM (CL) : Chan-Lawrence [20] の方法による LM 法

- LM (proposed)：提案方法による LM 法 ${ }^{* * * *}$

-VM: BFGS 公式による可変計量法（直線探索なし）

-VM (MT)：BFGS 公式による可変計量法 (Moré-Thuente 法 [39] による直線探索付き)

* SD における更新則は次式とした。

$$
\boldsymbol{q}_{k+1}=\boldsymbol{q}_{k}-\frac{E_{k}}{\boldsymbol{g}_{k}^{\mathrm{T}} \boldsymbol{g}_{k}} \boldsymbol{g}_{k}
$$

これは評価関数 $E(\boldsymbol{q})$ を $\boldsymbol{q}_{k}$ のまわりで局所的に二次関数近似 し推定した最小点に基づくものである.

** MP 逆行列解の求解は, 特異值分解よりも高速な LQ 分解 を用いて実装した。詳細は付録 B に記す。

*** LM (NH), LM (MWM), LM (Chi) はそれぞれ文献 に従って実装した。いずれも最大減衰因子小よび閾值を設計定 数として含むが, それらの決め方は自明ではない，本章での試 験に㧧いては試行錯誤的に Table 1 に示す值に設定した. 少な くとも実施した試験において, 計算時間や計算精度の観点から これらの值よりも良好な結果を示す值の組を見出すことは困難 であった。

**** 提案方法に扔いては $\bar{w}_{N}=1.0 \times 10^{-3}$ とした.

すべての反復計算に扮いて $\boldsymbol{W}_{E}=1$ とし, 初期值は毎回 $\boldsymbol{q}_{0}=\left[\begin{array}{lllll}0 & 0 & 0 & 0 & 0\end{array}\right]^{\mathrm{T}}$ にリセットした，これが特異点であること に注意されたい，反復計算はすべて，次の条件のうちいずれか が満たされた時点で終了とした。

i） $\Delta \boldsymbol{q}_{k}$ のすべての成分が $\epsilon=1.0 \times 10^{-12}$ 未満

ii) $\left\|\boldsymbol{e}_{k}\right\|$ の前回からの変化分が $\delta=1.0 \times 10^{-12}$ 未満

iii）反復回数が 10,000 回を超えた
Table 1 Parameters for LM (NH), LM (MWM) and LM (Chi)

\begin{tabular}{|c||c|c|c|}
\hline method & max. & threshold & recital \\
\hline LM(NH) & 0.1 & $2.0 \times 10^{-4}$ & manipulability \\
LH(MWM $)$ & 0.001 & $1.0 \times 10^{-2}$ & condition number \\
LH(Chi) & 0.1 & $1.0 \times 10^{-2}$ & minimum singular value \\
\hline
\end{tabular}

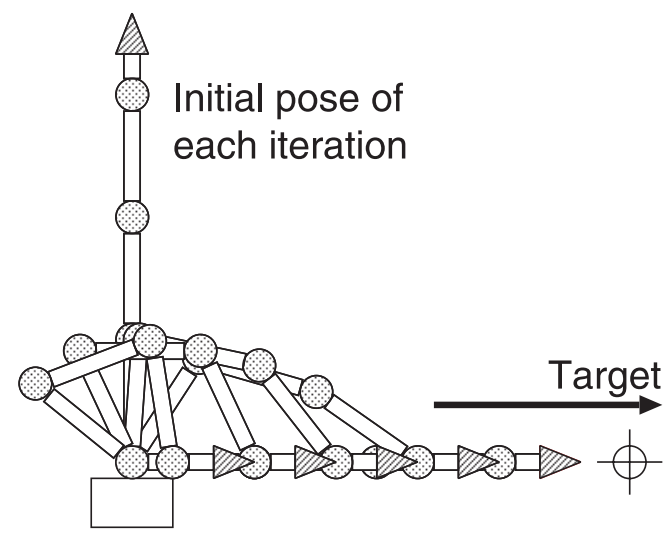

Fig. 2 In the first test, the target position of the endpoint is moved from 0.1 to $1.0[\mathrm{~m}]$ step-by-step

まずFig. 2 のように, エフェクタ目標位置・姿勢を

$$
{ }^{d} \boldsymbol{p}=\left[\begin{array}{c}
x_{d} \\
0 \\
0
\end{array}\right], \quad{ }^{d} \boldsymbol{R}=\left[\begin{array}{ccc}
0 & 0 & 1 \\
0 & 1 & 0 \\
-1 & 0 & 0
\end{array}\right]
$$

とし， 0.1 から 1.0 の間を 50 等分した值を $x_{d}$ とする 50 とおり のケースについて逆運動学を解く試験を行った．マニピュレー 夕の最大伸展長は $0.5[\mathrm{~m}]$ なので, $x_{d} \geq 0.5$ のときに逆運動学 は不可解となる. 上記 12 種の方法の計算終了時残差ノルム掠よ び計算時間を，それぞれFig. 3 抢よびFig. 4 に示す. Fig. 3 の 点線は, 理論上の目標位置・姿勢からの最小残差ノルムを表す. すなわち計算終了時残差ノルムを表す点がこの点線上に位置す るならば，計算が成功したことを意味する，LM (CL) と LM (proposed）のみがすべてのケースで成功した．ただし Fig. 4 (g) に見られるように, LM $(\mathrm{CL})$ では $x_{d}=0.5$ 付近で収束性能 が悪化している. SD, GN, LM $(\lambda=0.001,0.01,0.1)$, LM $(\mathrm{NH}), \mathrm{LM}(\mathrm{MWM}), \mathrm{LM}(\mathrm{Chi})$ は問題が不可解なケースで 頻繁に計算に失敗している.VM はこの例では比較的成功率が 高いが, いくつかのケースで結果が発散しており，しかもどの ような条件で発散するのかが明らかでない，またVM（MT） ではすべての結果が極小解に陥り，最小解に到達することはな かった。

次に, 可解となる限界である $x_{d} \simeq 0.5$ 付近での様子を調べる ため, 0.49 から 0.51 の間を 50 等分した值を $x_{d}$ とする 50 と おりのケースについて逆運動学を解く試験を行った。計算終了 時残差ノルムおよび計算時間をそれぞれ Fig. 5 および Fig. 6 に示す. LM $(\lambda=0.001,0.01,0.1), \mathrm{LM}(\mathrm{NH}), \mathrm{LM}(\mathrm{Chi})$ および LM（proposed）はすべてのケースで計算に成功してい る.ただし Fig. $6(\mathrm{c})(\mathrm{d})(\mathrm{e})(\mathrm{f})(\mathrm{h})$ から分かるように， $x_{d}$ がちょ うど 0.5 のときにはいずれの方法でも収束性の悪化を免れない ことは, 注意すべき点である. 一方, 前章で述べたとおり, LM (CL) はこの付近では頻繁に失敗している。VMはやはり不規 


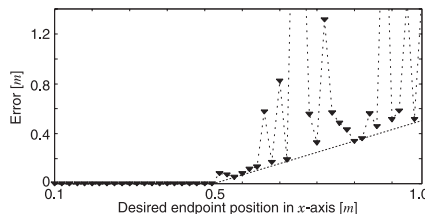

(a) SD

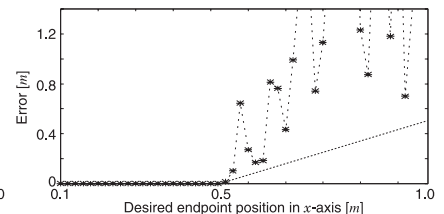

(b) GN

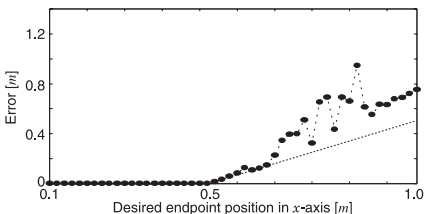

(c) $\operatorname{LM}(\lambda=0.001)$

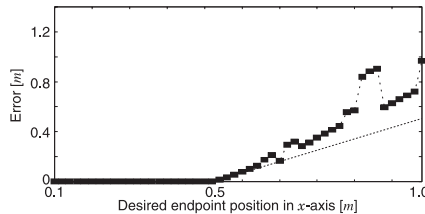

(e) $\operatorname{LM}(\lambda=0.1)$

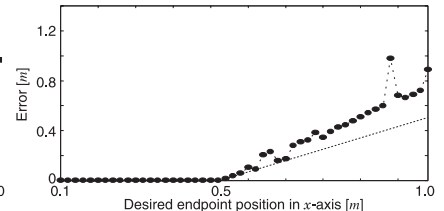

(f) $\operatorname{LM}(\mathrm{NH})$

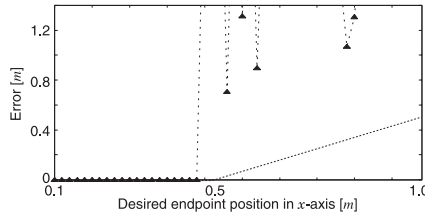

(i) $\mathrm{LM}(\mathrm{MWM})$

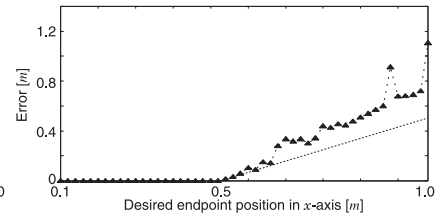

(j) $\operatorname{LM}(\mathrm{Chi})$

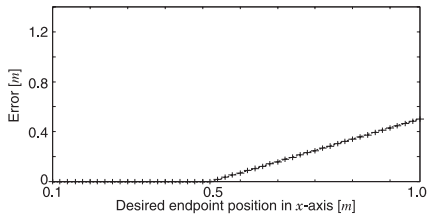

(g) $\operatorname{LM}(\mathrm{CL})$

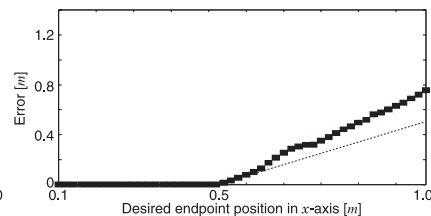

(d) $\operatorname{LM}(\lambda=0.01)$

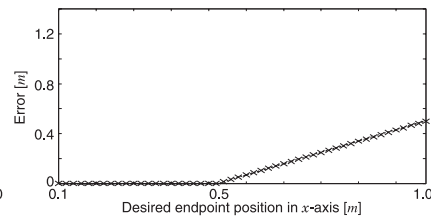

(h) LM(proposed)

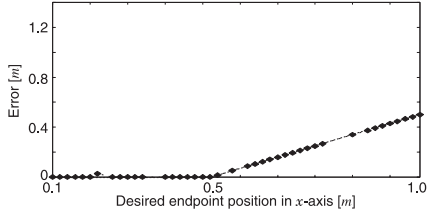

(k) VM

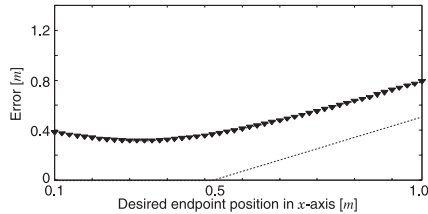

(1) $\operatorname{VM}(\mathrm{MT})$

Fig. 3 Error comparison between $\mathrm{SD}, \mathrm{GN}, \mathrm{LM}(\lambda=$ const. $), \mathrm{LM}(\mathrm{NH}), \mathrm{LM}(\mathrm{CL})$, LM(proposed), LM(MWM), LM(Chi), VM and VM(MT). Except for LM(CL) and LM(proposed), all methods failed to achive the minimum solution particularly in unsolvable range. VM made the results diverged in some cases. All results of $\operatorname{VM}(\mathrm{MT})$ were captured by local minima

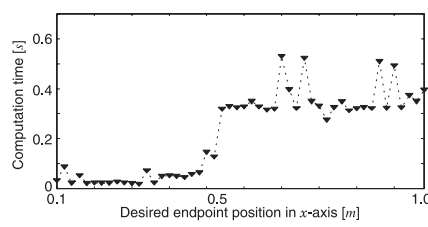

(a) SD

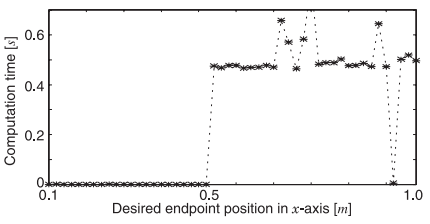

(b) GN

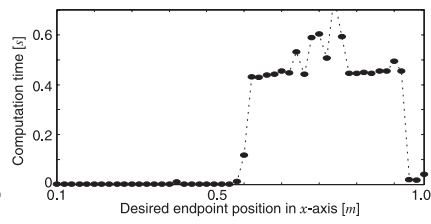

(c) $\operatorname{LM}(\lambda=0.001)$

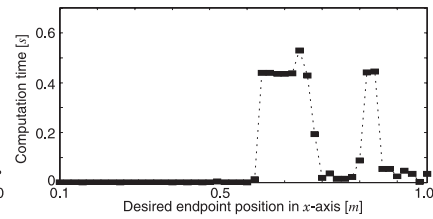

(d) $\operatorname{LM}(\lambda=0.01)$

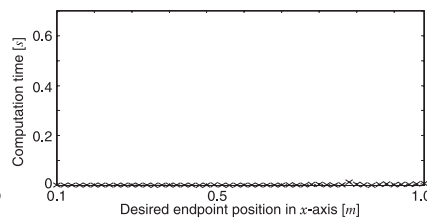

(h) LM(proposed)

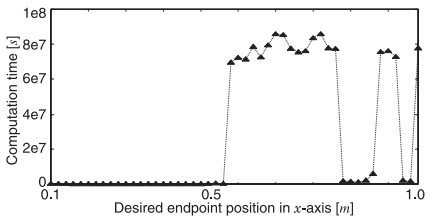

(j) $\mathrm{LM}(\mathrm{Chi})$

(g) $\mathrm{LM}(\mathrm{CL})$
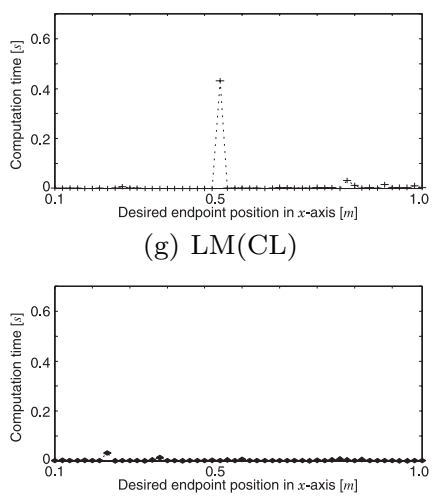

(k) VM

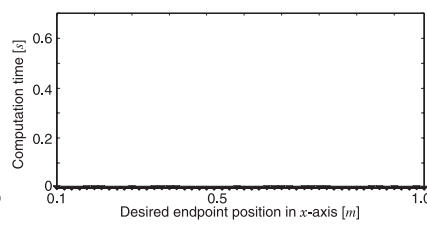

(l) $\mathrm{VM}(\mathrm{MT})$

Fig. 4 Computation time comparison between SD, GN, $\operatorname{LM}(\lambda=$ const.), $\operatorname{LM}(\mathrm{NH})$, $\mathrm{LM}(\mathrm{CL}), \mathrm{LM}$ (proposed), LM(MWM), LM(Chi), VM and VM(MT). Except for the proposed method, all methods failed to terminate iterations in some cases. Particularly, LM(Chi) consumed incomparably long time. Though the result of $\mathrm{VM}(\mathrm{MT})$ showed fast convergences, they were all captured by local minima. Refer the caption of Fig. 3

則に計算に失敗し, VM（MT）はすべてのケースで極小解に 陥っている. $x_{d}$ を特異点近傍である 0.502 としたときの, 各方 法の反復計算過程における評価関数の変化を Fig. 7 に示す（た だし LM $(\lambda=0.01,0.1), \mathrm{VM}$ はプロットしていない). 理論 上, SD は一次収束, LM (CL), LM (Proposed) は超一次収
束，ほかは二次収束となるが，それをよく表している，同図左 では LM（CL）も収束しているように見えるが，反復回数 7 ス テップ以降の様子を示した同図右を見ると，LM（CL）は実は 計算の最終段でなかなか収束していないことが分かる．Fig. 8 は各方法の反復計算過程に扔ける条件数の変化を示したもので, 


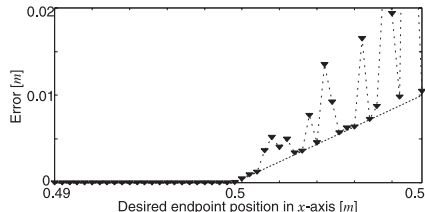

(a) $\mathrm{SD}$

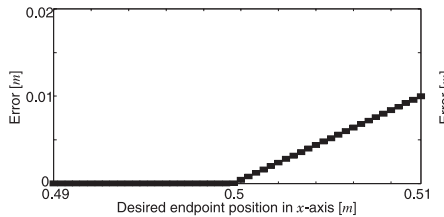

(e) $\operatorname{LM}(\lambda=0.1)$

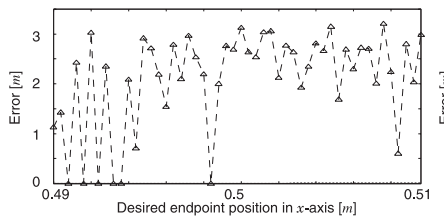

(i) $\operatorname{LM}(\mathrm{MWM})$

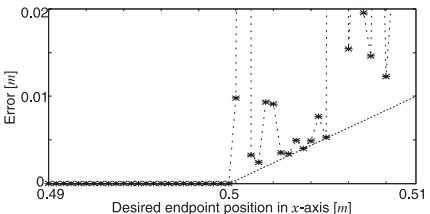

(b) GN

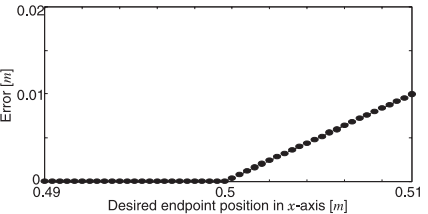

(f) $\mathrm{LM}(\mathrm{NH})$

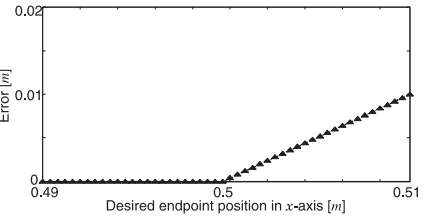

(j) $\mathrm{LM}(\mathrm{Chi})$

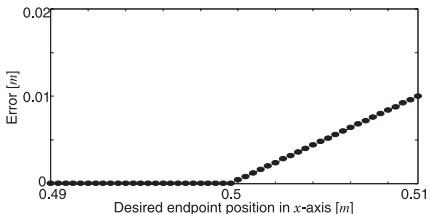

(c) $\operatorname{LM}(\lambda=0.001)$

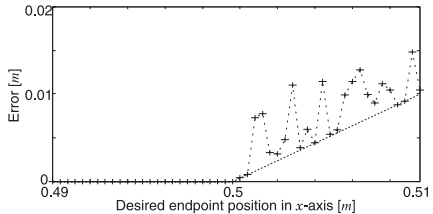

(g) $\mathrm{LM}(\mathrm{CL})$

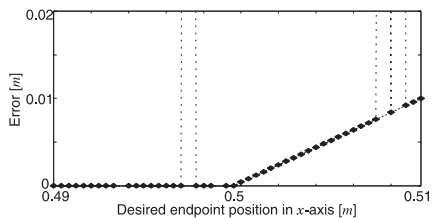

(k) VM

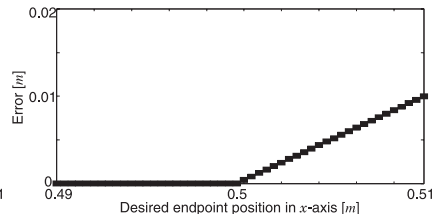

(d) $\operatorname{LM}(\lambda=0.01)$

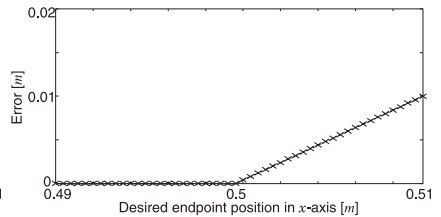

(h) LM(proposed)

Fig. 5 Error comparison between $\mathrm{SD}, \mathrm{GN}, \mathrm{LM}(\lambda=$ const. $), \mathrm{LM}(\mathrm{NH}), \mathrm{LM}(\mathrm{CL})$, $\mathrm{LM}$ (proposed), LM(MWM), LM(Chi), VM and $\mathrm{VM}(\mathrm{MT})$ near the boundary of the solvable range. While $\mathrm{LM}(\mathrm{CL})$ showed unstable behavior, the proposed method succeeded in all cases. Although LM(Chi) showed successful results, it consumed long time for computations. See Fig. 6

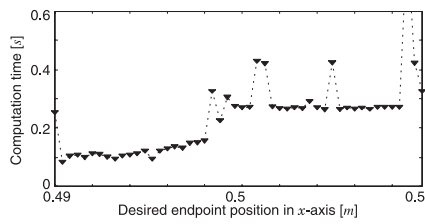

(a) SD

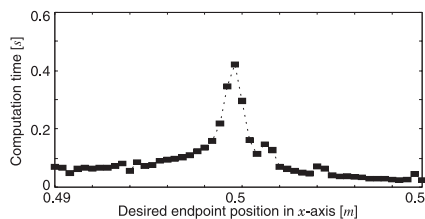

(e) $\operatorname{LM}(\lambda=0.1)$

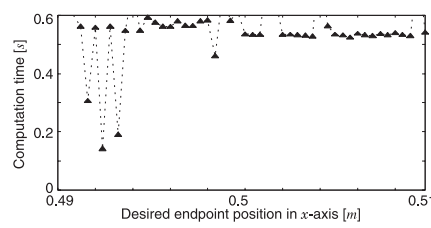

(i) $\operatorname{LM}(\mathrm{MWM})$

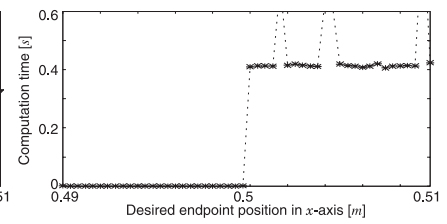

(b) GN

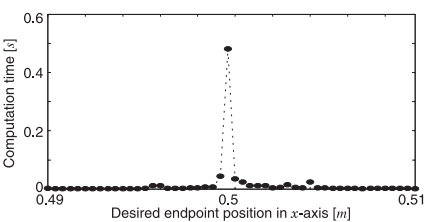

(f) $\operatorname{LM}(\mathrm{NH})$

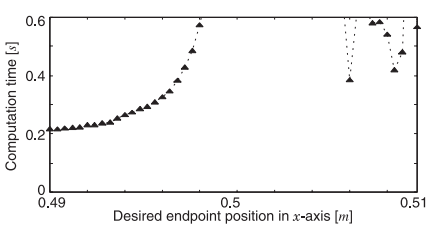

(j) $\operatorname{LM}(\mathrm{Chi})$

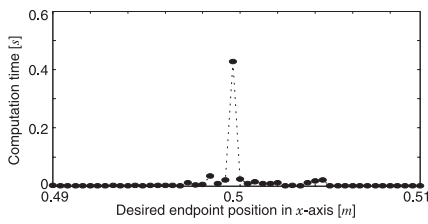

(c) $\operatorname{LM}(\lambda=0.001)$

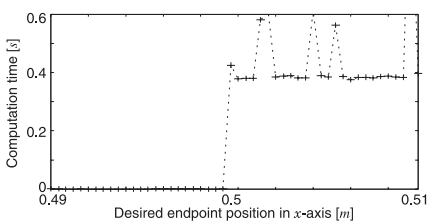

(g) $\mathrm{LM}(\mathrm{CL})$

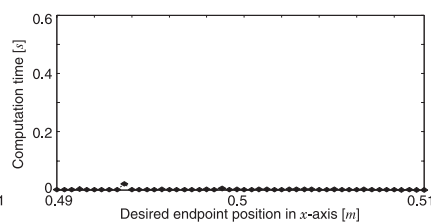

(k) VM

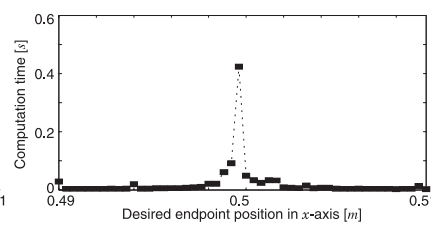

(d) $\operatorname{LM}(\lambda=0.01)$

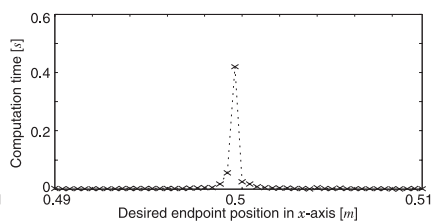

(h) LM(proposed)

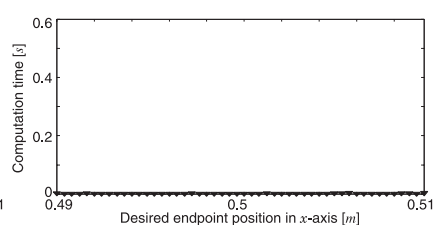

(l) $\mathrm{VM}(\mathrm{MT})$

Fig. 6 Computation time comparison between $\mathrm{SD}, \mathrm{GN}, \operatorname{LM}(\lambda=$ const. $), \operatorname{LM}(\mathrm{NH})$, $\mathrm{LM}(\mathrm{CL}), \mathrm{LM}$ (proposed), LM(MWM), LM(Chi), VM and VM(MT) near the boundary of the solvable range. Though the proposed method took long time exactly at the boundary, the result was correct. Also, any other methods didn't show better performance than the proposed method

LM（Proposed）が他の成功した方法と同様に 16 程度に収束 しているのに対し, LM（CL）は数十～百強の範囲で変動し ていた。このため収束性が悪くなっていたと考えられる。

最後に，第 1 関節位置を中心とした一辺 $1.2[\mathrm{~m}]$ の立方領域内 で乱数的にエフェクタ目標位置・姿勢を生成し, 逆運動学を解く
試験を 1,000 回行った。ただし, LM（Chi）は計算時間が他の 方法に比べ桁違いに長いため除外した。それぞれの方法での計 算成功率と成功時の平均計算時間を, 計算成功率の高い順に並 べたものを Table 2 に示す。ただし本試験においてはそれぞれ のケースに扔ける最小解が分からないため, 12 種類の方法で得 

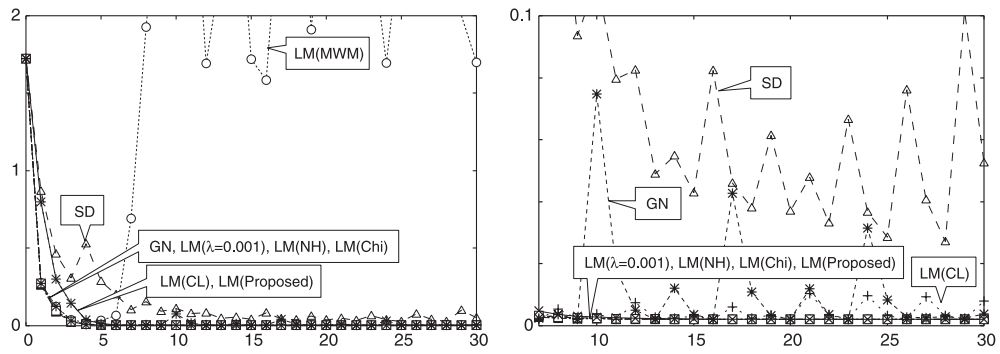

Fig. 7 History of weighted squared residual in iterations (left: from 0 to 300 step, right: from 7 to 300 step)

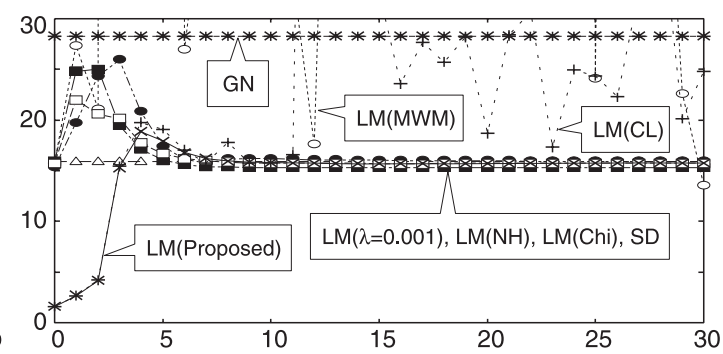

Fig. 8 History of condition number in iterations
Table 2 Result of random test $\times 1,000$. The configuration was initialized for the home position every time. The target position and orientation of the effector were set within $1.2 \times 1.2 \times 1.2$ cubic area

\begin{tabular}{|l||r|r|}
\hline method & rate of success & $\begin{array}{r}\text { ave. computation } \\
\text { time }[\mu \mathrm{s}]\end{array}$ \\
\hline $\mathrm{LM}($ proposed $)$ & $1,000 / 1,000$ & 2,227 \\
$\mathrm{LM}(\mathrm{CL})$ & $935 / 1,000$ & 2,267 \\
$\mathrm{LM}(\lambda=0.1)$ & $277 / 1,000$ & 19,265 \\
$\mathrm{LM}(\lambda=0.01)$ & $276 / 1,000$ & 4,161 \\
$\mathrm{LM}(\lambda=0.001)$ & $255 / 1,000$ & 1,819 \\
$\mathrm{LM}(\mathrm{NH})$ & $240 / 1,000$ & 2,197 \\
$\mathrm{GN}$ & $211 / 1,000$ & 417 \\
$\mathrm{SD}$ & $211 / 1,000$ & 52,431 \\
$\mathrm{LM}(\mathrm{MWM})$ & $191 / 1,000$ & 99,305 \\
$\mathrm{VM}$ & $1 / 1,000$ & 1,776 \\
$\mathrm{VM}(\mathrm{MT})$ & $0 / 1,000$ & - \\
\hline
\end{tabular}

た残差ノルムとそれらの最小值との差が $1.0 \times 10^{-6}$ 未満である 場合を成功と見なした，提案方法のみすべてのケースで成功し ていることは特筆すべき点である。ほか，LM (CL) 以外は失 敗することの方が多かった，特に VM（MT）はすべてのケー スで失敗した，先の試験では比較的成功の多かった VM も，本 試験では 1 ケースでしか成功しておらず，可変計量法は一般的 に信頼性が非常に低いと言える。計算時間については，GN が 最も速いのは当然だが, 提案方法の 5 倍程度であり, 他の比較 的成功率の高い $\mathrm{LM}(\mathrm{CL}), \mathrm{LM}(\lambda=0.001), \mathrm{LM}(\mathrm{NH})$ と も比肩する結果となっている. すなわち提案方法は, 高い計算 成功率と引き換えに計算時間を犠牲にしているわけではない.

以上の結果より，提案方法は最も実用性が高いと言える.

\section{5. 応用例}

提案した逆運動学解法の応用事例として, 人型ロボット運動 編集ソフトウェアを実装した。 山根・中村 [40] の提案したピン・ ドラッグ・インタフェースを用い, 直感的に操作を行えるものと した. そのスナップショットを Fig. 9 に示す。このようなソフ トウェアで問題となるのは, 拘束条件とロボット自由度の大小 関係が頻繁に変化することであり, 特に拘束条件のほうが多い （過拘束な）場合は必然的に不可解問題となる。したがって提案 方法のような，可解性を問わない逆運動学解法が不可欠である.

Fig. 9 のそれぞれの状況において, 拘束条件の数は左上で 12 (右足位置・姿勢, 左足爪先 2 点の位置), 右上で 15 (前記に加 え左手先位置), 左下で 18 (前記に加え右手先位置), 右下で 18
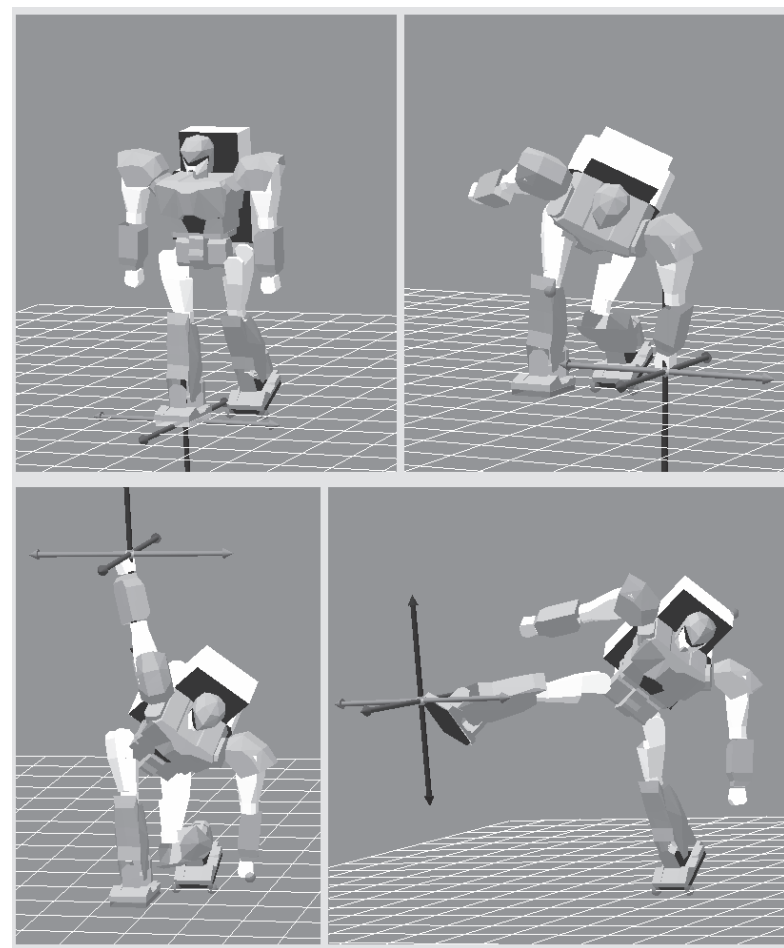

Fig. 9 Snapshots of a humanoid robot motion editor

（右足位置・姿勢，左足爪先 2 点の位置，胴体位置・姿勢）と なっている，上の二つは，圥長な場合であっても問題なく，要 求された拘束条件を満たす姿勢に収束していることを示す例で ある，左下の状況では，右手先を高く突き上げる姿勢をとらせ るために目標位置を可動範囲外に設定している。すなわちこの 例では不可解問題の求解を要求しており，したがってこの姿勢 は特異点である。また右下の，胴体に対して右足を伸ばしきっ た姿勢を編集する過程では，胴体と左足を互いに引き離すよう に目標位置・姿勢を動かす操作を繰り返し，そのため途中姿勢 が何度も特異点に入った。 これらの例においても，ロボットの 挙動が振動的になったり, 特異点に陥って脱出できなくなった りするなどの計算の破綻を起こすことなく操作を継続できた.

山根らの作成したソフトウェアでは反復計算は行っておらず, 関心リンクの位置・姿勢に比例補償速度を持たせることによっ て目標点に収束させている。このため収束性能は関心リンク速 度と微分逆運動学演算性能の双方に依存する。筆者の作成した ソフトウェアでは毎回反復計算を行っているが, ベースリンク 
6 自由度を含めた 26 自由度の人型ロボットモデル [41] に対し て十分インタラクティブな運動編集を行える。また，零空間を 用いた優先度付き微分逆運動学 [42] は用いておらず, ピン拘束 の重みを 1.0 , ドラッグハンドル拘束の重みを 0.1 としている. 実際のロボットは関節可動範囲が制限される。本ソフトウェ アでは，毎回の反復計算で可動範囲を超えた関節変位は強制的 に可動限界でリセットするという単純な方法で, 問題 (QP) に 不等式制約条件が課されたときの Kuhn-Tucker 条件を自動的 に満足している.

\section{6.お おりに}

特異点や圥長性, 問題の可解性に対してもロバストに計算を 行える, LM 法によるロボット逆運動学の数值解法を提案した. これは，残差二乗ノルムに微小なバイアスを加えたものを減衰 因子に用いるという単純な方法であり, 可操作度や係数行列の 最小特異值等を求める重い付加的な計算を要求しない. それに もかかわらず，計算成功率の高さにおいて従来方法に対する格 段の優位性を示している。実際，筆者のこれまでの経験で計算 が発散したことは一度もない。理論的に超一次収束することが 期待され，試験的にも十分実用に耐える計算速度を持つことを 確認した，微小バイアスの決定方法には議論の余地があるが， 3 章に記したように，ロボットの代表的リンク長を二乗した值の $1.0 \times 10^{-1} \sim 1.0 \times 10^{-3}$ 倍程度ならば十分ロバストな収束性を 示すことが経験的に分かった，比較的大きな範囲にわたって值 を選べることは，計算結果がこの值に対しそれほどセンシティ ブではないということを意味している。これは従来の方法が設 計定数を決めるための具体的目安を持たず，しかもその值によっ て大きく結果が変わってしまうことに比べ有利なことと言える.

この技術は，人型ロボットのような大規模な多リンクロボッ トの運動設計ツールや，遠隔操縦システムにおいて，ロボット 工学に必ずしも精通していないユーザでも多様な運動を容易に かつ安全に設計できるようにするツール開発のための基盤技術 になると期待できる。

謝 辞 本研究は, 科学研究費補助金若手研究 (A) 内課題 「力学変容系としての人の運動理解と次世代人型ロボット制御の 基盤構築」（課題番号：22680018）および次世代研究スーパース ター養成プログラム（九州大学総長裁量経費）の支援を受けた。

\section{参 考 文 献}

[1] D.L. Pieper: "The Kinematics of Manipulators under Computer Control," PhD thesis, Stanford University, 1968.

[2] M. Raghavan and B. Roth: "Kinematic Analysis of the 6R Manipulator of General Geometry," Proceedings of The Fifth International Symposium on Robotics Research, pp.263-269, 1991.

[3] M. Raghavan and B. Roth: "Solving Polynomial Systems for the Kinematic Analysis and Synthesis of Mechanisms and Robot Manipulators," Transaction of the ASME, Special 50th Anniversary Design Issue, vol.117, pp.71-79, 1995.

[4] S. Sasaki: "Feasibility Studies of Kinematic Problems in the Case of a Class of Redundant Manipulators," Robotica, vol.13, pp.233-241, 1995

[ 5 ] O. Khatib: "A Unified Approach for Motion and Force Control of Robot Manipulators: The Operational Space Formulation,"
The International Journal of Robotics and Automation, vol. RA-3, no.1, pp.43-53, 1987.

[6] D.E. Whitney: "The Mathematics of Coordinated Control of Prosthetic Arms and Manipulators," Transactions of the ASME, Journal of Dynamic Systems, Measurement, and Control, vol.94, no.4, pp.303-309, 1972.

[ 7 ] D.E. Orin and W.W. Schrader: "Efficient Computation of the Jacobian for Robot Manipulators," The International Journal of Robotics Research, vol.3, no.4, pp.66-75, 1984.

[ 8 ] 内山勝：“人工の手の運動制御に関する研究（第 1 報，特異点を考慮し た協調運動の計算)”, 日本機械学会論文集 (C 編)，vol.45, no.391, pp.314-322, 1979

[9] J. Baillieul: "Kinematic Programming Alternatives for Redundant Manipulators," Proceedings of the 1985 IEEE International Conference on Robotics \& Automation, pp.722-728, 1985.

[10] 中村仁彦, 花房秀郎：“関節型ロボットアームの特異点低感度運動分 解”，計測自動制御学会論文集，vol.20, no.5, pp.453-459, 1984.

[11] C.W. Wampler II: "Manipulator Inverse Kinematic Solutions Based on Vector Formulations and Damped Least-Squares Methods," IEEE Transactions on Systems, Man, and Cybernetics, vol.SMC-16, no.1, pp.93-101, 1986.

[12] D.N. Nenchev, Y. Tsumaki and M. Uchiyama: "SinguralityConsistent Behavior of Telerobots: Theory and Experiments," The International Journal of Robotics Research, vol.17, no.2, pp.138-152, 1998

[13] K. Levenberg: "A Method for the Solution of Certain Nonlinear Problems in Least Squares," Quarterly of Applied Mathematics, vol.2, pp.4164-4168, 1944.

[14] D.W. Marquardt: "An Algorithm for Least-Squares Estimation of Nonlinear Parameters," Journal of the Society for Industrial and Applied Mathematics, vol.11, no.2, pp.431-441, 1963.

[15] Y. Nakamura and K. Yamane: "Dynamics Computation of Structure-Varying Kinematic Chains and Its Application to Human Figures," IEEE Transactions on Robotics and Automation, vol.16, no.2, pp.124-134, 2000

[16] W.A. Wolovich and H. Elliot: "A Computational Technique for Inverse Kinematics," Proceedings of the 23rd IEEE conference on Decision and Control, pp.1359-1363, 1984.

[17] A. Balestrino, G. de Maria and L. Sciavicco: "Robust Control of Robotic Manipulators," Proceedings of the 9th IFAC World Congress, vol.5, pp.2435-2440, 1984.

[18] L.T. Wang and C.C. Chen: "A Combined Optimization Method for Solving the Inverse Kinematics Problem of Mechanical Manipulators," IEEE Transactions on Robotics and Automation, vol.7, no.4, pp.489-499, 1991.

[19] J. Zhao and N.I. Badler: "Inverse Kinematics Positioning Using Nonlinear Programming for Highly Articulated Figures," ACM Transactions on Graphics, vol.13, no.4, pp.313-336, 1994.

[20] S.K. Chan and P.D. Lawrence: "General Inverse Kinematics with the Error Damped Pseudoinverse," Proceedings of the 1988 IEEE International Conference on Robotics \& Automation, pp.834-839, 1988.

[21] E.D. Pohl and H. Lipkin: "A New Method of Robotic Motion Control Near Singularities," Proceedings of the Fifth IEEE International Conference on Advanced Robotics, pp.405-410, 1991.

[22] K.A. O'Neil, Y. Chen and J. Seng: "Removing Singularities of Resolved Motion Rate Control of Mechanisms, Including Self-Motion," IEEE Transactions on Robotics and Automation, vol.13, no.5, pp.741-751, 1997.

[23] A. Hourtash: "The Kinematic Hessian and Higher Derivatives," Proceedings of the 2005 IEEE International Symposium on Computational Intelligence in Robotics and Automation, pp.169-174, 2005.

[24] A.S. Deo and I.D. Walker: "Adaptive Non-linear Least Squares for Inverse Kinematics," Proceedings of IEEE International 
Conference on Robotics and Automation, pp.186-193, 1993.

[25] J.E. Dennis, Jr. and R.B. Schnabel: Numerical Methods for Unconstrained Optimization and Nonlinear Equations. Society for Industrial and Applied Mathematics, 1993.

[26] K. Anderson and J. Angeles: "Kinematic Inversion of Robotic Manipulators in the Presence of Redundancies," The International Journal of Robotics Research, vol.8, no.6, pp.80-97, 1989.

[27] A.A. Goldenberg, B. Benhabib and R.G. Fenton: "A Complete Generalized Solution to the Inverse Kinematics of Robots," IEEE Journal of Robotics and Automation, vol.RA-1, no.1, pp.14-20, 1985.

[28] G.H. Golub, P.C. Hansen and D.P. O'Leary: "Tikhonov Regularization and Total Least Squares," SIAM Journal of Matrix Analysis and Applications, vol.21, no.1, pp.185-194, 1999.

[29] T. Yoshikawa: "Manipulability of Robotic Mechanisms," The International Journal of Robotics Research, vol.4, no.2, pp.3-9, 1985.

[30] L. Kelmar and P. Khosla: "Automatic Generation of Kinematics for a Reconfigurable Modular Manipulator System," Proceedings of the IEEE International Conference on Robotics \& Automation, pp.663-668, 1988.

[31] S. Chiaverini: "Estimate of the Two Smallest Singular Values of the Jacobian Matrix: Applications to Damped Least-Squares Inverse Kinematics," Journal of Robotic Systems, pp.991-1008, 1988.

[32] S. Chiaverini, B. Siciliano and O. Egeland: "Review of Damped Least-Squares Inverse Kinematics with Experiments on an Industrial Robot Manipulator," IEEE Transactions on Control Systems Technology, vol.2, pp.123-134, 1994.

[33] A.A. Maciejewski and C.A. Klein: "Numerical Filtering for the Operation of Robotic Manipulators Through Kinematically Singular Configurations," Journal of Robotic Systems, vol.5, no.6, pp.527-552, 1988.

[34] R.V. Mayorga, A.K.C. Wong and N. Milano: "A Fast Procedure for Manipulator Inverse Kinematics Evaluation and Pseudoinverse Robustness," IEEE Transactions on Systems, Man, and cybernetics, vol.22, pp.790-798, 1992.

[35] A.A. Maciejewski and C.A. Klein: "The Singular Value Decomposition: Computation and Applications to Robotics," International Journal of Robotic Research, vol.8, pp.63-79, 1989.

[36] A.S. Deo and I.D. Walker: "Robot Subtask Performance with Singularity Robustness Using Optimal Damped Least Squares," Proceedings of IEEE International Conference on Robotics and Automation, pp.434-441, 1992.

[37] Y. Choi: "Singularity-Robust Inverse Kinematics Using Lagrange Multiplier for Redundant Manipulators," Transaction of ASME, Journal of Dynamic Systems, Measurement, and Control, vol.130, no.5, pp.051009-1-7, 2008.

[38] N. Yamashita and M. Fukushima: "On the Rate of Convergence of the Levenberg-Marquardt Method," Computing, vol.[Suppl] 15, no.237-249, 2001.

[39] J.J. Moré and D.J. Thuente: "Line Search Algorithms with Guaranteed Sufficient Decrease," ACM Transactions on Mathematical Software, vol.20, no.3, pp.286-307, 1994.

[40] K. Yamane and Y. Nakamura: "Natural Motion Animation through Constraining and Deconstraining at will," IEEE Transactions on Visualization and Computer Graphics, vol.9, no.3, pp.352-360, 2003.

[41] T. Sugihara, K. Yamamoto and Y. Nakamura: "Hardware design of high performance miniature anthropomorphic robots," Robotics and Autonomous System, vol.56, pp.82-94, 2007.

[42] A.A. Maciejewski and C.A. Klein: "Obstacle Avoidance for Kinematically Redundant Manipulators in Dynamically Varying Environments," International Journal of Robotic Research, vol.4, no.3, pp.109-117, 1985.

[43] J.Y.S. Luh, M.W. Walker and R.P.C. Paul: "Resolved Acceler- ation Control of Mechanical Manipulators," IEEE Transactions on Automatic Control, vol.AC-25, no.3, pp.468-474, 1980.

\section{付録 A． 姿勢行列から等価角軸ベクトルへの变換}

姿勢行列 $\boldsymbol{R}=\left\{r_{i j}\right\} \in S O(3)(i=1 \sim 3, j=1 \sim 3)$ に対 し，次のベクトルを定義する.

$$
\boldsymbol{l} \equiv\left[\begin{array}{l}
r_{32}-r_{23} \\
r_{13}-r_{31} \\
r_{21}-r_{12}
\end{array}\right]
$$

$\boldsymbol{R}$ が対角行列でなければ $\boldsymbol{l}$ は零ベクトルではなく, これより $\boldsymbol{R}$ と等価な角軸べクトル $\boldsymbol{a}$ は次のように計算される。

$$
\boldsymbol{a}(\boldsymbol{R}) \equiv \frac{\operatorname{atan} 2\left(\|\boldsymbol{l}\|, r_{11}+r_{22}+r_{33}-1\right)}{\|\boldsymbol{l}\|} \boldsymbol{l}
$$

$\boldsymbol{R}$ が対角行列の場合， $\left(r_{11}, r_{22}, r_{33}\right)=(1,1,1),(1,-1,-1)$, $(-1,1,-1),(-1,-1,1)$ の四つの可能性が考えられる.もし $\left(r_{11}, r_{22}, r_{33}\right)$ のうち二つが -1 であれば, $\boldsymbol{a}$ は次のように定 義できる。

$$
\boldsymbol{a} \equiv \frac{\pi}{2}\left[\begin{array}{l}
r_{11}+1 \\
r_{22}+1 \\
r_{33}+1
\end{array}\right]
$$

また，もし $\left(r_{11}, r_{22}, r_{33}\right)=(1,1,1)$ ならば $\boldsymbol{a} \equiv \mathbf{0}$ となる.

Luh ら [43] は， $\boldsymbol{a}$ ではなく式（A.1）に打ける $\boldsymbol{l}$ をそのまま姿 勢誤差評価に用いる方法を提案しているが，これは上記のよう に $\boldsymbol{R}$ が対角行列となる四つの場合を正しく判別できない。ここ で示した方法は，そのような問題を解決したものになっている，

\section{付録 B. LQ 分解による重み付き MP 逆行列解}

基礎ヤコビ行列 $\boldsymbol{J}_{k}$ を，次のように二つの行列 $\boldsymbol{L}, \boldsymbol{Q}$ の積に 分解する。

$$
\boldsymbol{J}_{k}=\boldsymbol{L} \boldsymbol{Q}
$$

ただし $\boldsymbol{L}$ は列フルランクな下三角行列， $\boldsymbol{Q}$ は正規直交行列で ある。このような操作は任意の $\boldsymbol{J}$ に対して可能であり, LQ 分 解と呼ばれる。

$\boldsymbol{J}_{k}$ の MP 逆行列 $\boldsymbol{J}_{k}^{*}$ は, $\boldsymbol{L}$ と $\boldsymbol{Q}$ を用いて次のように計算 される。

$$
\boldsymbol{J}_{k}^{*}=\boldsymbol{Q}^{\mathrm{T}}\left(\boldsymbol{L}^{\mathrm{T}} \boldsymbol{W}_{e} \boldsymbol{L}\right)^{-1} \boldsymbol{L}^{\mathrm{T}} \boldsymbol{W}_{E}
$$

$\mathrm{MP}$ 逆行列解を用いる場合, 実装上は, 方程式 $\boldsymbol{L}^{\mathrm{T}} \boldsymbol{W}_{E} \boldsymbol{L} \boldsymbol{v}=$ $\boldsymbol{L}^{\mathrm{T}} \boldsymbol{W}_{E} \boldsymbol{e}_{k}$ をまずガウス消去法によって $\boldsymbol{v}$ について解き，ささら に $\boldsymbol{q}_{k+1}=\boldsymbol{q}_{k}+\boldsymbol{Q}^{\mathrm{T}} \boldsymbol{v}$ とすれば計算効率がよい

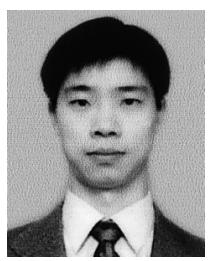

杉原知道 (Tomomichi Sugihara)

1999 年東京大学工学部機械情報工学科卒業, 2004 年同大学大学院情報理工学系研究科知能機械情報 学専攻博士課程修了. 同年同専攻学術研究支援員. 2005 年より 2007 年まで同専攻助手. 九州大学高等 研究院特別准教授を経て, 2010 年より大阪大学工 学研究科知能・機能創成工学専攻准教授. 博士（情 報理工学)。人型ロボットの運動学, 力学, 運動計画と制御, 操縦シ ステム開発, ハードウェア設計, ソフトウェアシステム開発等に関す る研究に従事. IEEE の会員.

(日本ロボット学会正会員) 